\title{
Hydrolytic dehydrogenation of ammonia borane over ZIF-67 derived Co nanoparticle catalysts
}

Zacho, Simone Louise; Mielby, Jerrik Jørgen; Kegnæs, Søren

Published in:

Catalysis Science \& Technology

Link to article, DOI:

10.1039/C8CY01500G

Publication date:

2018

Document Version

Peer reviewed version

Link back to DTU Orbit

Citation (APA):

Zacho, S. L., Mielby, J. J., \& Kegnæs, S. (2018). Hydrolytic dehydrogenation of ammonia borane over ZIF-67 derived Co nanoparticle catalysts. Catalysis Science \& Technology, 8, 4741-4746.

https://doi.org/10.1039/C8CY01500G

\section{General rights}

Copyright and moral rights for the publications made accessible in the public portal are retained by the authors and/or other copyright owners and it is a condition of accessing publications that users recognise and abide by the legal requirements associated with these rights.

- Users may download and print one copy of any publication from the public portal for the purpose of private study or research.

- You may not further distribute the material or use it for any profit-making activity or commercial gain

- You may freely distribute the URL identifying the publication in the public portal 


\section{Accepted Manuscript}

This article can be cited before page numbers have been issued, to do this please use: S. L. Zacho, J. Mielby and S. Kegnæs, Catal. Sci. Technol., 2018, DOI: 10.1039/C8CY01500G.

\section{Catalysis Science \& Technology}
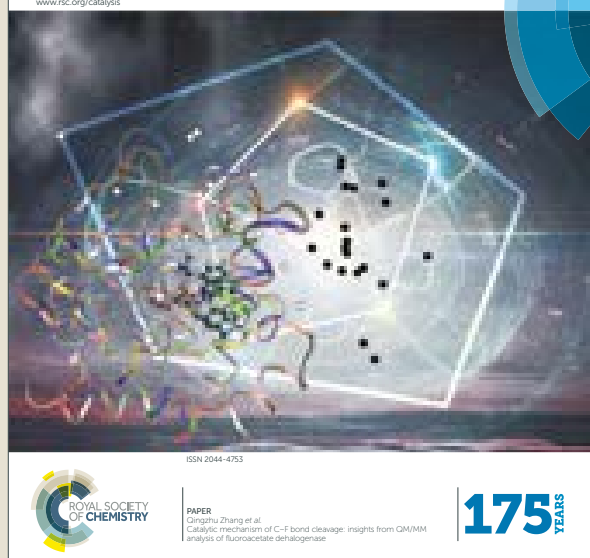

175
This is an Accepted Manuscript, which has been through the Royal Society of Chemistry peer review process and has been accepted for publication.

Accepted Manuscripts are published online shortly after acceptance, before technical editing, formatting and proof reading. Using this free service, authors can make their results available to the community, in citable form, before we publish the edited article. We will replace this Accepted Manuscript with the edited and formatted Advance Article as soon as it is available.

You can find more information about Accepted Manuscripts in the author guidelines.

Please note that technical editing may introduce minor changes to the text and/or graphics, which may alter content. The journal's standard Terms \& Conditions and the ethical guidelines, outlined in our author and reviewer resource centre, still apply. In no event shall the Royal Society of Chemistry be held responsible for any errors or omissions in this Accepted Manuscript or any consequences arising from the use of any information it contains. 


\section{Journal Name}

\section{ARTICLE}

\section{Hydrolytic dehydrogenation of ammonia borane over ZIF-67 derived Co nanoparticle catalysts}

Received 00th January 20xx, Accepted 00th January 20xx

DOI: $10.1039 / x 0 x x 00000 x$ www.rsc.org/

\begin{abstract}
Simone Louise Zacho, ${ }^{a}$ Jerrik Mielby ${ }^{a}$ and Søren Kegnæs ${ }^{a} *$
In this work, we exploited zeolitic imidazolate framework ZIF-67 as sacrificial precursors to prepare Co nanoparticles supported on nanoporous nitrogen-doped carbon. The catalysts were tested for hydrolytic dehydrogenation of ammonia borane and the size of the Co nanoparticles and the structural features of the carbon support were shown to have a large effect on the catalytic activity. Furthermore, we investigated the effect of adding $\mathrm{Zn}$ to the catalyst precursor (ZIF-67/8). The highest catalytic activity was obtained from $\mathrm{ZIF}-67 / 8$ with a molar ratio of $\mathrm{Co} / \mathrm{Zn}=1$, which was carbonized at $900^{\circ} \mathrm{C}$ to

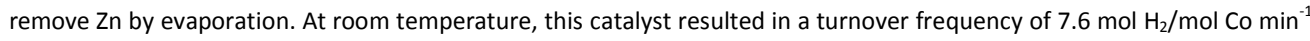
and an apparent activation energy of $E_{a}=44.9 \mathrm{~kJ} / \mathrm{mol}$. The turnover frequency was further increased to $12.7 \mathrm{~min}^{-1}$ in $0.1 \mathrm{M}$ $\mathrm{NaOH}$.
\end{abstract}

\section{Introduction}

Hydrogen produced from renewable resources holds great promise as a solution to future energy and environmental challenges. ${ }^{1}$ In particular, hydrogen may power fuel cells, which can generate electricity without emission of greenhouse gasses. Unfortunately, the physical properties of hydrogen gas make transportation, handling and refuelling difficult. Much effort has therefore been devoted to the development of chemical hydrogen storage materials. ${ }^{2,3,4,5}$ In these types of materials, chemical processes control hydrogen storage and release. This makes them different from metal hydrides ${ }^{6}$ or carbon materials, ${ }^{7}$ where temperature and pressure control storage and release. One compound, ammonia borane $\left(\mathrm{H}_{3} \mathrm{NBH}_{3}\right)$, has attracted particular attention because of its high volumetric and gravimetric density. Ammonia borane is solid at room temperature, stable in air and water and contains around $196 \mathrm{~g} / \mathrm{kg}$ or $100-140 \mathrm{~g} / \mathrm{l}$ of $\mathrm{H}_{2}{ }^{8}$ In combination with an efficient catalyst, the hydrolytic dehydrogenation of ammonia borane is given by

1) $\mathrm{H}_{3} \mathrm{NBH}_{3}(\mathrm{aq})+2 \mathrm{H}_{2} \mathrm{O}(\mathrm{l}) \rightarrow \mathrm{NH}_{4}\left(\mathrm{BO}_{2}\right)(\mathrm{aq})+3 \mathrm{H}_{2}(\mathrm{~g})$

In a protic solvent like $\mathrm{H}_{2} \mathrm{O}$, up to three equivalents of $\mathrm{H}_{2}$ can be released from ammonia borane and when a proper catalyst is used, hydrogen can be released under ambient conditions. In the past years, a number of efficient noble metal catalysts have been developed for the hydrolytic

\footnotetext{
a. S. L. Zacho, Dr. J. Mielby, Prof. S. Kegnæs

DTU Chemistry, Technical University of Denmark

Kemitorvet Building 207

DK-2800 Kgs. Lyngby, Denmark

Electronic Supplementary Information (ESI) available: [details of any supplementary information available should be includ ed here]. See DOI: 10.1039/x0xx00000x
}

dehydrogenation of $\mathrm{H}_{3} \mathrm{NBH}_{3}$, including both homogeneous ${ }^{9}$ and heterogeneous catalysts based on $\mathrm{Pt}^{10} \mathrm{Rh}^{11} \mathrm{Ru}^{12} \mathrm{Ag}^{13}$ and $\mathrm{Pd}^{14}$. Considering the limited availability and high cost of noble metals, the development of equally active and more cost-effective non-noble metal catalysts is of great interest. ${ }^{15}$ Among the non-noble metals, Co supported on carbon has recently been suggested as a promising catalyst because of its high activity ${ }^{16}$ and magnetic properties. These properties make is easy to collect the supported nanoparticles from the liquid phase. ${ }^{17,18,19}$ For instance, Wang et al. ${ }^{20}$ recently embedded Co nanoparticles in porous nitrogen-doped carbon, which was synthesized by carbonization of a Co(salen) precursor under $\mathrm{Ar}$ atmosphere. The Co nanoparticles resulted in a turnover

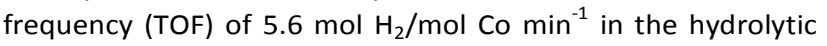
dehydrogenation of ammonia borane. The catalyst showed good stability over 10 runs collecting the catalyst using a permanent magnet after each run. The porosity of these type of carbon materials is a key factor for the catalytic activity.

Here, we report a method to prepare Co nanoparticles supported on a porous nitrogen-doped carbon matrix synthesized by carbonization. The method exploits metal organic frameworks (MOFs) as sacrificial precursors for both the cobalt nanoparticles and the nitrogen-doped carbon matrix support. Because of their remarkable chemical and structural properties, such as their high surface area and welldefined porosity, MOFs have recently attracted much interest for applications in gas adsorption, separation and heterogeneous catalysis. ${ }^{21,22}$ Furthermore, MOFs have recently been used for preparation of high-surface area nanoporous carbons for electrochemical reactions. ${ }^{23}$

In this work, we carbonized different zeolitic imidazolate frameworks comprised of Co and 2-methylimidazole (ZIF-67) and investigated the catalytic effect of the particle size and the carbonization temperature. Furthermore, we investigated the 
effect of adding Zn (bimetallic hybrid of ZIF-67/8) in order to control the Co loading in the catalyst precursor. We carbonized the ZIFs at high temperatures to remove the $\mathrm{Zn}$ by evaporation according to Yin et al. ${ }^{24}$ The best catalyst resulted in a turnover

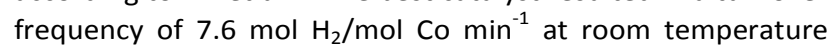
without base. The activity was further tested in $0.1 \mathrm{M} \mathrm{NaOH}$ and $\mathrm{KOH}$, which increased the TOF to $12.7 \mathrm{~min}^{-1}$ in $0.1 \mathrm{M} \mathrm{NaOH}$ and $11.0 \mathrm{~min}^{-1}$ in $0.1 \mathrm{M} \mathrm{KOH}$ in agreement with previous reports. $^{25,26}$

\section{Experimental}

Materials. All reagents were purchased from commercial source (Sigma-Aldrich) and used without further purifications, including $\mathrm{Co}\left(\mathrm{NO}_{3}\right)_{2} \cdot 6 \mathrm{H}_{2} \mathrm{O}(>99.9 \%), \mathrm{Zn}\left(\mathrm{NO}_{3}\right)_{2} \cdot 6 \mathrm{H}_{2} \mathrm{O}(>99.9 \%), 2$ methylimidazole (99\%), methanol (HPLC Plus, $\geq 99.9 \%$ ) and ammonia borane $\left(\mathrm{H}_{3} \mathrm{NBH}_{3}, 97 \%\right)$.

Synthesis of ZIF-67. ZIF-67 was synthesized in methanol according to the literature. ${ }^{27}$ In brief, $\mathrm{Co}\left(\mathrm{NO}_{3}\right)_{2} \cdot 6 \mathrm{H}_{2} \mathrm{O}(1.436 \mathrm{~g})$ and 2-methylimidazole ( $3.244 \mathrm{~g})$ were each dissolved in 100 $\mathrm{mL}$ of methanol. The Co salt solution was then poured into the ligand solution and vigorously stirred in a round-bottomed flask for $12 \mathrm{~min}$ at the desired temperature $\left(25^{\circ} \mathrm{C}\right.$ or $\left.60^{\circ} \mathrm{C}\right)$. The solution was left without stirring for $24 \mathrm{~h}$ at $25^{\circ} \mathrm{C}$. The purple product was collected by centrifugation, thoroughly washed with methanol three times and then dried at $80^{\circ} \mathrm{C}$ for $24 \mathrm{~h}$. The yield of ZIF-67 was $75 \%$ based on the amount of Co. The synthesis temperatures $\left(25^{\circ} \mathrm{C}\right.$ or $\left.60^{\circ} \mathrm{C}\right)$ yielded ZIF-67 with crystal sizes of $300 \mathrm{~nm}$ and $500 \mathrm{~nm}$ respectively (ZIF-67-300 and ZIF-67-500).

Synthesis of ZIF-67/8. The bimetallic hybrid of ZIF-67 and ZIF-8 (ZIF-67/8) was synthesized with a ratio of $\mathrm{Co} / \mathrm{Zn}=1$. The material was prepared according to the synthesis of pure ZIF67 , except that the salt solution consisted of both $\mathrm{Co}\left(\mathrm{NO}_{3}\right)_{2} \cdot 6 \mathrm{H}_{2} \mathrm{O}(0.718 \mathrm{~g})$ and $\mathrm{Zn}\left(\mathrm{NO}_{3}\right)_{2} \cdot 6 \mathrm{H}_{2} \mathrm{O}(0.734 \mathrm{~g})$. After the synthesis, the purple product was collected, washed and dried as described above. The yield of ZIF- $67 / 8$ was $79 \%$ based on the amount of Co and Zn. The synthesis yielded ZIF-67/8 with an average crystal size of $50 \mathrm{~nm}$ (ZIF-67/8-50).

Synthesis of carbonised catalysts. ZIF-67 and ZIF-67/8 were carbonized in a tube furnace at a temperature of $750^{\circ} \mathrm{C}$ or $900^{\circ} \mathrm{C}$ for 2 hours under $\mathrm{Ar}$ using a heating ramp of $5^{\circ} \mathrm{C} / \mathrm{min}$. The final catalysts were labelled according to the rough size of the parent catalyst precursor in $\mathrm{nm}$. Figure 1 illustrates the two steps of the synthesis, including crystallization and carbonization, respectively. Table 1 shows an outline of all the prepared materials.

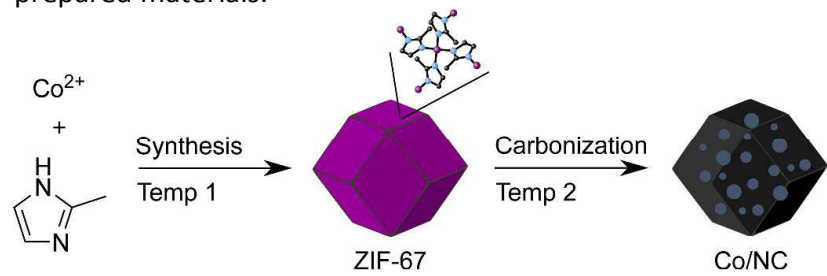

Figure 1. Illustration of the catalyst synthesis.

Table 1. Outline of the prepared materials.

\begin{tabular}{lllll}
\hline Entry & Step 1 & Precursor $^{\mathrm{a}}$ & Step 2 & Catalyst $^{\mathrm{a}}$ \\
\hline 1 & $60^{\circ} \mathrm{C}$ & ZIF-67-500 & $750^{\circ} \mathrm{C}$ & $\mathrm{Co} / \mathrm{NC}-500$ \\
2 & $25^{\circ} \mathrm{C}$ & ZIF-67-300 & $750^{\circ} \mathrm{C}$ & $\mathrm{Co} / \mathrm{NC}-300$ \\
3 & $25^{\circ} \mathrm{C}$ & ZIF-67/8-50 & $750^{\circ} \mathrm{C}$ & CoZn/NC-50 \\
4 & $25^{\circ} \mathrm{C}$ & ZIF-67/8-50 & $900^{\circ} \mathrm{C}$ & Co/NC-50 \\
\hline
\end{tabular}

${ }^{\mathrm{a}}$ The names of the prepared materials are distinguished by the crystal sizes of the catalyst precursors (given in $\mathrm{nm}$ ).

Characterisation. The prepared materials were characterised by X-ray diffraction (XRD), $\mathrm{N}_{2}$ physisorption, scanning electron microscopy (SEM) and transmission electron microscopy (TEM). Please see supporting information for all experimental details.

Catalytic tests. The catalytic activity was tested in an automated gas burette system equipped with a pressure transducer to follow the displacement of a light silicone oil upon the release of $\mathrm{H}_{2}$ gas. ${ }^{28}$ Before each experiment, 10-20 $\mathrm{mg}$ of the catalyst was added to a round bottom flask together with a magnet. The flask was then sealed with a septum and connected to the gas burette system before a solution of 50 $\mathrm{mg} \mathrm{H}_{3} \mathrm{NBH}_{3}$ in $10 \mathrm{ml} \mathrm{H}$ O was quickly injected into the flask using a syringe. The catalysts were applied without activation by addition of $\mathrm{NaBH}_{4}$, which is commonly used in literature. $^{20,29,30}$ The reaction was either stirred at room temperature or heated using an oil bath, while the data were collected and analysed using an online computer. The system was calibrated using a mass flow controller and the release of $\mathrm{H}_{2}$ calculated from the linear calibration line.

\section{Results and discussion}

Figure 2a shows XRD analysis of ZIF-67-300, ZIF-67-500 and ZIF-67/8-50, respectively. The three diffraction patterns show that all catalyst precursors have the characteristic ZIF-67 sodalite structure, with clear and well-resolved peaks at $2 \theta$ equal $7^{\circ}(011), 13^{\circ}(112)$ and $18^{\circ}(222) .^{24,31}$ Figure $2 b$ shows the corresponding materials after carbonization $\mathrm{Co} / \mathrm{NC}-300$, Co/NC-500 and CoZn/NC-50 at $750^{\circ} \mathrm{C}$ as well as Co/NC-50 at $900^{\circ} \mathrm{C}$. As expected, the carbonization results in a complete decomposition of the crystalline ZIF structure. Here, the XRD shows a broad diffraction band around $20^{\circ}$ as well as a smaller band at $26^{\circ}$. We attribute these bands to the diffraction of amorphous carbon with some graphitic-like structure. ${ }^{32}$ 

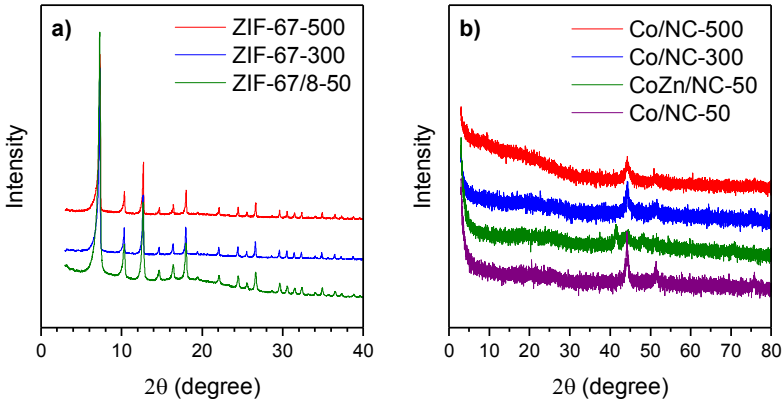

$\begin{array}{lllll}6 & \text { CoZn/NC-50 } & 335 & 179 & 0.065 \\ 7 & \text { Co/NC-50 } & 312 & 184 & 0.058\end{array}$

ARTICLE
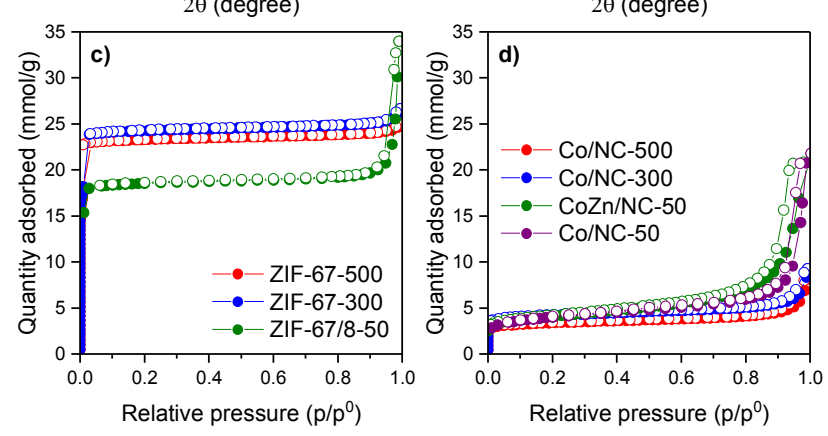

Figure 2. XRD and $\mathrm{N}_{2}$ physisorption analysis of the prepared materials before (left, a \& c) and after carbonization (right, b \& d).

Furthermore, the XRD shows three diffraction peaks at $2 \theta$ equal $44^{\circ} \mathrm{Co}(111), 52^{\circ} \mathrm{Co}(200)$ and $76^{\circ} \mathrm{Co}(220)$, which confirms the formation of face-centred cubic Co nanoparticles. ${ }^{24}$ In general, the peaks are too weak to determine the average particle size by line-broadening analysis. Enlarged versions of the XRD patterns of Co/NC-300 and $\mathrm{Co} / \mathrm{NC}-500$ are shown in the supporting information.

Figure $2 \mathrm{c}$ and $2 \mathrm{~d}$ show the $\mathrm{N}_{2}$ physisorption analysis of the catalyst precursors before and after carbonization, respectively. While ZIF-67-500nm and ZIF-67-300nm have type I isotherms, which are typical for MOFs and other microporous materials, ${ }^{33}$ ZIF-67/8-50 is absorbing less $N_{2}$ at low relative pressures and more $\mathrm{N}_{2}$ at high relative pressures. We assign the lower micropore volume in ZIF-67/8-50 to the partial substitution of $\mathrm{Co}$ by $\mathrm{Zn}$ in the framework and the higher mesopore volume to interparticle porosity. After the carbonization, the physisorption analysis results in isotherms with character of both type I and IV. The results from the physisorption analysis are summarised in Table 2 and the corresponding pore size distributions are shown in the supporting information.

Table 2. Summary of results from $\mathrm{N}_{2}$ physisorption analysis.

\begin{tabular}{llllll}
\hline Entry & Material & $\begin{array}{l}\mathrm{S}_{\mathrm{BET}}{ }^{\mathrm{a}} \\
\left(\mathrm{m}^{2} / \mathrm{g}\right)\end{array}$ & $\begin{array}{l}\mathrm{S}_{\mathrm{ext}}{ }^{\mathrm{b}} \\
\left(\mathrm{m}^{2} / \mathrm{g}\right)\end{array}$ & $\begin{array}{l}\mathrm{V}_{\text {micro }}{ }^{\mathrm{b}} \\
\left(\mathrm{cm}^{3} / \mathrm{g}\right)\end{array}$ & $\begin{array}{l}\mathrm{V}_{\text {tot }}{ }^{\mathrm{d}} \\
\left(\mathrm{cm}^{3} / \mathrm{g}\right)\end{array}$ \\
\hline 1 & ZIF-67-500 & 1951 & 67 & 0.779 & 0.842 \\
3 & ZIF-67-300 & 1848 & 72 & 0.811 & 0.884 \\
4 & ZIF-67/8-50 & 1379 & 90 & 0.603 & 0.719 \\
5 & Co/NC-500 & 290 & 74 & 0.085 & 0.210 \\
5 & Co/NC-300 & 356 & 96 & 0.103 & 0.233
\end{tabular}

a Specific surface area determined by the BET method, ${ }^{b}$ external surface area and micropore volume determined by the $t$-plot method and ${ }^{d}$ total pore volume determined by a single point read at $\mathrm{p} / \mathrm{p}^{0}=0.95$.

Figure 3 shows representative SEM images of the prepared materials before (left) and after carbonization under $\mathrm{Ar}$ at $750^{\circ} \mathrm{C}$ for $2 \mathrm{~h}$ (right). All the catalyst precursors are typical rhombic dodecahedral in shape. Depending on the crystallization temperature, the average crystal size of the ZIF67 is around $500 \mathrm{~nm}$ (for crystallization at $60^{\circ} \mathrm{C}$ ) or around 300 $\mathrm{nm}$ (for crystallization at $25^{\circ} \mathrm{C}$ ). By adding $\mathrm{Zn}\left(\mathrm{NO}_{3}\right)_{2}$ to the synthesis the average size of the crystals decreases to around $50 \mathrm{~nm}$. After carbonization, Co/NC-500 and Co/NC-300 preserve the shape of their catalyst precursors, although the structures shrink and the sides of the dodecahedrons become more concave. The CoZn-NC-50 catalyst does not retain the shape of its precursor, but appears as larger agglomerates. The corresponding SEM image of Co/NC-50 is similar to CoZn/NC50 and is shown in the supporting information.
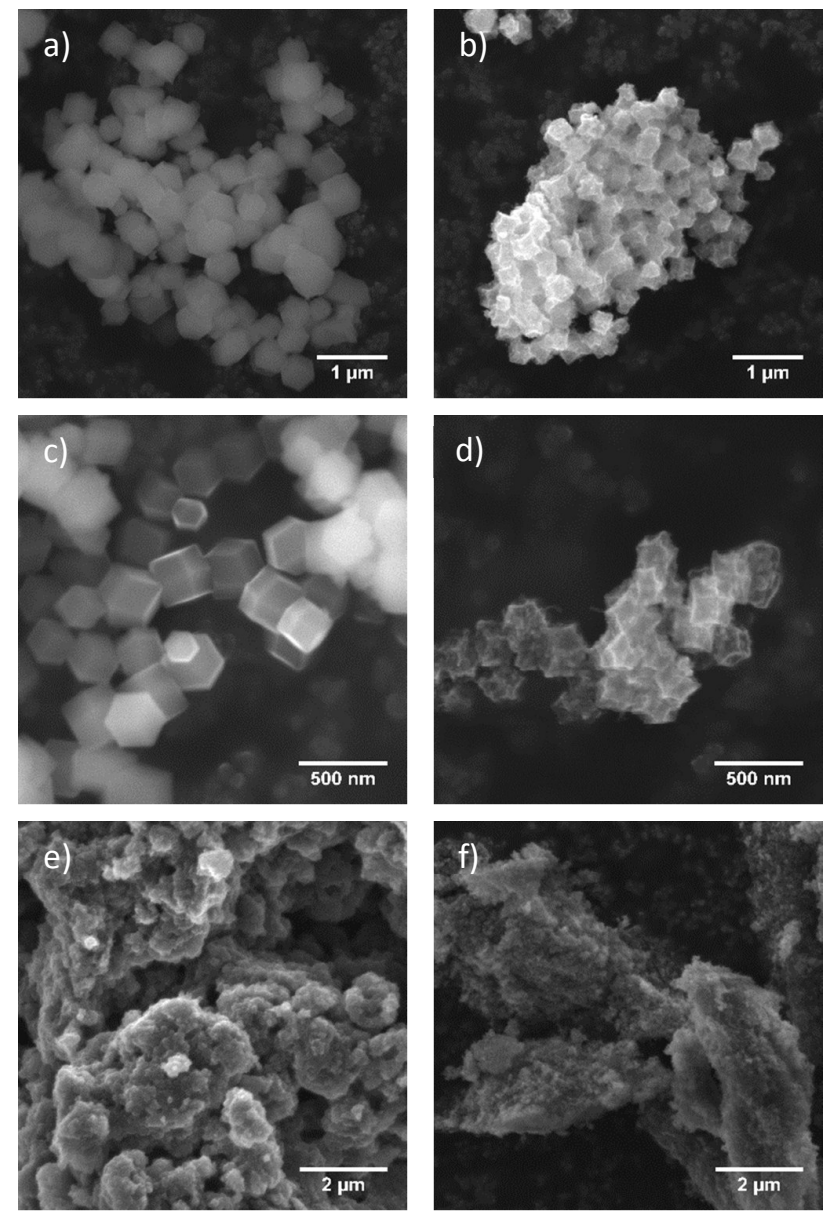

Figure 3. SEM images of a) ZIF-67-500, b) Co/NC-500, c) ZIF-67-300, d) Co/NC-300, e) ZIF-67/8-50 and f) CoZn/NC-50. 

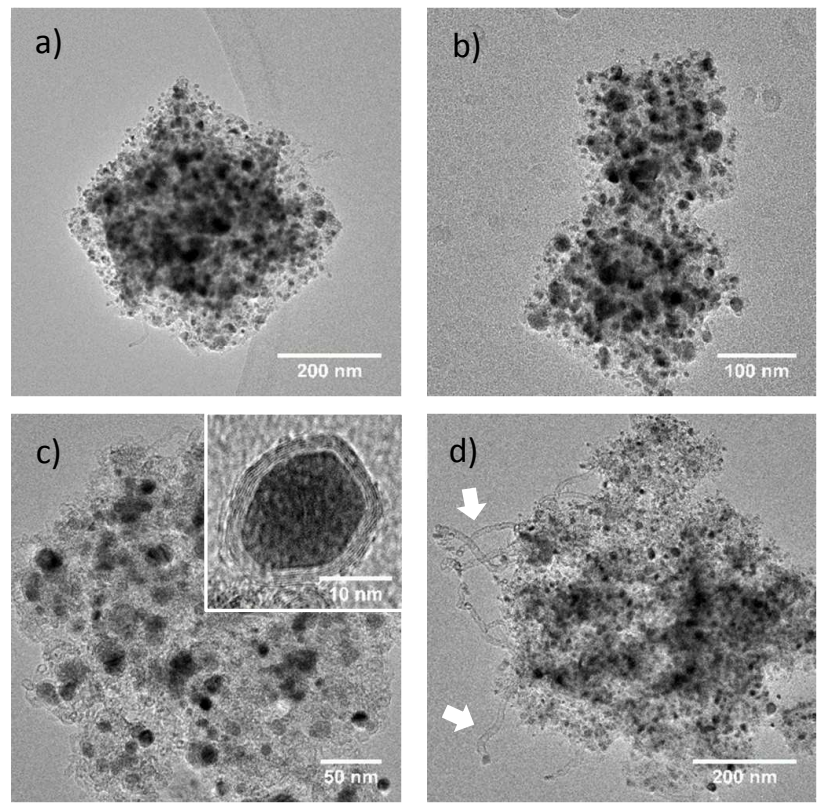

Figure 4. TEM images of a) Co/NC-500, b) Co/NC-300, c) CoZn/NC50, d) Co/NC-50.

Figure 4 shows representative TEM images of Co/NC-500, $\mathrm{Co} / \mathrm{NC}-300, \mathrm{CoZn} / \mathrm{NC}-50$ and Co/NC-50, respectively. Considering the high metal to carbon ratio, all precursors result in relatively well-dispersed Co nanoparticles, typically in the range of 5-25 nm. While Co/NC-500 and Co/NC-300 have a Co loading of $18 \mathrm{wt} \%, \mathrm{Co} / \mathrm{NC}-50$ only has a Co loading of 8 wt\%. As expected, the nanoparticles in $\mathrm{Co} / \mathrm{NC}-50$ are therefore smaller, typically in the range of 5-15 $\mathrm{nm}$. By changing the $\mathrm{Co} / \mathrm{Zn}$ ratio it is therefore possible to control both the particles size and the Co loading. As reference materials ZIF-67-500 and ZIF-67-300 were also carbonized at $900^{\circ} \mathrm{C}$, which results in large agglomerations of Co nanoparticles with an average size of $100 \mathrm{~nm}$, see supporting information. We speculate that optimisation of the carbonization procedure may result in even smaller nanoparticles. The TEM images also reveal how the carbonization of the catalyst precursors results in the formation of graphitic carbon in Figure $4 c$ and a network of carbon nanotubes that protrudes from the catalyst in Figure 4d. The TEM images of the catalyst precursors ZIF-67-500, ZIF67-300 and ZIF-67/8-50 are shown in the supporting information.

Figure 5 shows the volume of released $\mathrm{H}_{2}$ from the catalytic dehydrogenation of ammonia borane over the first 45 min using $20 \mathrm{mg}$ of catalyst and $50 \mathrm{mg}$ of $\mathrm{H}_{3} \mathrm{NBH}_{3}$ in $10 \mathrm{ml} \mathrm{H}_{2} \mathrm{O}$ at $25^{\circ} \mathrm{C}$.
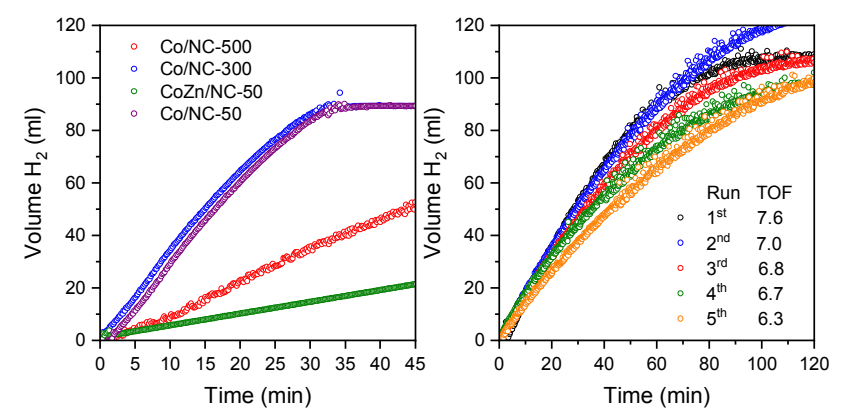

Figure 5. a) Volume of released $\mathrm{H}_{2}$ from the catalytic dehydrogenation of ammonia borane using $20 \mathrm{mg}$ catalyst at $25^{\circ} \mathrm{C}$. b) Recycle tests of Co/NC-50 using $10 \mathrm{mg}$ catalyst. TOF is given in

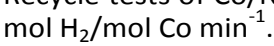

Table 3 shows the corresponding TOF values as calculated from the initial reaction rate and the metal loading $\left(\mathrm{mol} \mathrm{H}_{2} / \mathrm{mol} \mathrm{Co} \mathrm{min}^{-}\right.$ $\left.{ }^{1}\right)$. While Co/NC-500 only results in a TOF of $1.1 \mathrm{~min}^{-1}$, Co/NC-300 results in a TOF of $2.7 \mathrm{~min}^{-1}$, which may be explained by the higher surface area and porosity of $\mathrm{Co} / \mathrm{NC}-300$. These results demonstrate that even small changes in the synthesis of the catalyst precursors can have a significant effect on both the structural and catalytic properties. A similar effect was previously reported by Zou et al. for the oxygen reduction reaction. ${ }^{34}$ For both catalysts, the amount of $\mathrm{H}_{2}$ released per ammonia borane was around 2.4-2.5, which is less than the stoichiometric value of 3 (see equation 1 ), but in the same range as other non-noble metal catalysts. ${ }^{15}$ The reference materials ZIF-67-500 $\left(900^{\circ} \mathrm{C}\right)$ and ZIF-67-300 $\left(900^{\circ} \mathrm{C}\right)$ exhibited low activities in the dehydrogenation of ammonia borane, as expected due to the large agglomerations of Co nanoparticles, see supporting information.

Table 3. Results from the catalytic dehydrogenation of ammonia borane.

\begin{tabular}{llllll}
\hline Entry & Catalyst & Co wt\% $^{\mathrm{a}}$ & $\mathrm{AB} / \mathrm{Co}^{\mathrm{b}}$ & $\mathrm{H}_{2} / \mathrm{AB}^{\mathrm{b}}$ & $\begin{array}{l}\mathrm{TOF}^{\mathrm{c}} \\
\left(\mathrm{min}^{-1}\right)\end{array}$ \\
\hline 1 & Co/NC-500 & 18 & 26 & 2.4 & 1.1 \\
2 & Co/NC-300 & 18 & 26 & 2.5 & 2.7 \\
3 & CoZn/NC-50 & 4 & 60 & 2.7 & 1.8 \\
4 & Co/NC-50 & 8 & 126 & 2.9 & 7.6 \\
\hline
\end{tabular}

a Determined by atomic absorption spectroscopy (AAS).

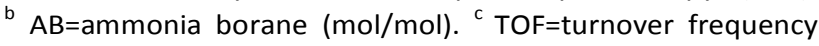

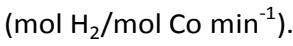

Table 3 shows that the bimetallic CoZn catalyst results in a TOF of $1.8 \mathrm{~min}^{-1}$ with a $\mathrm{H}_{2}$ to ammonia borane ratio of 2.7. It is notable that this catalyst was the least active with respect to the mass of the catalyst as shown in Figure 5. Thus, we speculate that the $\mathrm{Zn}$ may form an inactive CoZn alloy in this sample. ${ }^{35}$ By increasing the carbonization temperature from $750^{\circ} \mathrm{C}$ to $900^{\circ} \mathrm{C}$, which effectively removes the $\mathrm{Zn}$ by evaporation, the TOF increases to $7.6 \mathrm{~min}^{-1}$ for Co/NC-50. Furthermore, the released $\mathrm{H}_{2}$ to ammonia borane ratio increased to around 2.9 of the theoretical 3 equivalents, which corresponds to a yield of $97 \% .^{36,37}$ 
High turnover frequencies have previously been reported for a number of carbon supported Co catalysts, in particular for Co supported on graphene (Co/graphene, TOF=13.9 min $\left.{ }^{1}\right)^{29}$ and Co supported on graphene oxide modified by polyethylenimine (Co/PEI-GO, TOF $\left.=39.9 \mathrm{~min}^{-1}\right){ }^{30}$ Common for both systems is that $\mathrm{NaBH}_{4}$ is used to activate the catalysts. Unfortunately, these catalysts were also reported to suffer from severe deactivation retaining only $60-65 \%$ of the initial catalytic activity after 5 runs. For comparison, Figure 5 shows how the catalytic activity of Co/NC-50 also decreases over multiple runs. After 5 runs, however, the TOF is still $6.3 \mathrm{~min}^{-1}$, which corresponds to $83 \%$ of the initial catalytic activity. Based on TEM analysis we propose that the deactivation may be caused by a combination of particle aggregation and surface oxidation, see supporting information. Wang et al. previously reported that their catalyst prepared from $\mathrm{Co}($ Salen) with an initial TOF of $5.6 \mathrm{~min}^{-1}$ could be recycled up to 10 times. $^{20}$

Figure $6 a$ shows the effect of increasing the reaction temperature from $25-50^{\circ} \mathrm{C}$ using the $\mathrm{Co} / \mathrm{NC}-50$ catalyst. As expected, the increased temperature has a large effect on the initial reaction rate and at temperatures above $45^{\circ} \mathrm{C}$ all $\mathrm{H}_{2}$ is released in less than $25 \mathrm{~min}$. Figure $6 \mathrm{~b}$ shows the corresponding Arrhenius plot. The apparent activation energy as determined from the slope of the linear fit was calculated to $E_{a}=44.9 \mathrm{~kJ} / \mathrm{mol}$. Yang et al. ${ }^{8}$ have previously reported activation energies from $38-67 \mathrm{~kJ} / \mathrm{mol}$, which positions the Co/NC-50 catalysts in the better range with respect to the activation energy.
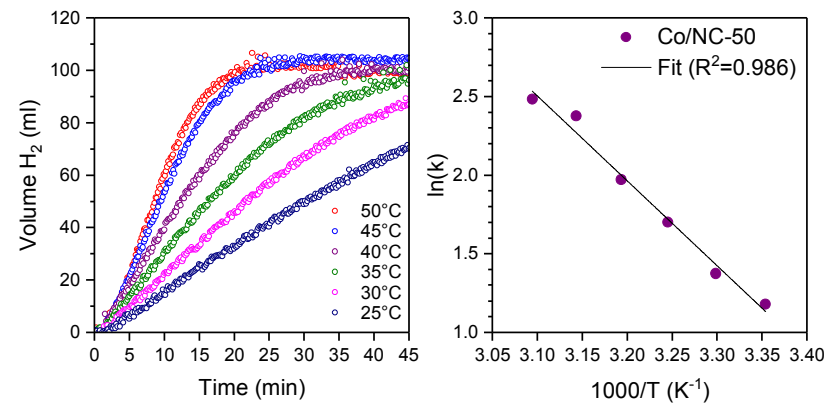

Figure 6. a) Effect of increasing the temperature from $25-50^{\circ} \mathrm{C}$ and $b$ ) the corresponding Arrhenius plot.

In agreement with previous reports, ${ }^{25}$ addition of base increased the reaction rate. In $0.1 \mathrm{M} \mathrm{KOH}$ the TOF increased to $11.0 \mathrm{~min}^{-1}$ and in $0.1 \mathrm{M} \mathrm{NaOH}$ the TOF increased to $12.7 \mathrm{~min}^{-1}$, see supporting information.

\section{Conclusions}

In conclusion, we exploited the zeolitic imidazolate framework ZIF-67 as sacrificial precursor for the preparation of Co nanoparticles supported on a porous nitrogen-doped carbon matrix. By changing the synthesis temperature, it was possible to control the size of the catalyst precursor crystals and the resulting catalyst particles, which retained the characteristic rhombic dodecahedral shape after carbonization. By addition of $\mathrm{Zn}$ to the ZIF synthesis, the size of the precursor crystals decreased to around $50 \mathrm{~nm}$, although the subsequent carbonization resulted in large and undefined agglomerates. The catalysts were tested for the hydrolytic dehydrogenation of ammonia borane and the catalytic activities were related to the size of the Co nanoparticles and the structural features of the carbon support. The highest catalytic activity was obtained from ZIF-67/8 with a molar ratio of $\mathrm{Co} / \mathrm{Zn}=1$, which was carbonized at $900^{\circ} \mathrm{C}$ to remove $\mathrm{Zn}$ by evaporation. At room temperature, this catalyst resulted in a turnover frequency of

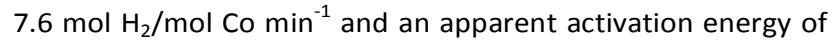
$\mathrm{Ea}=44.9 \mathrm{~kJ} / \mathrm{mol}$. Furthermore, it was possible to optimize the reaction in $0.1 \mathrm{M} \mathrm{KOH}$ and $\mathrm{NaOH}$, providing a final TOF of 11.0 $\mathrm{min}^{-1}$ and $12.7 \mathrm{~min}^{-1}$, respectively. We hope that these results will inspire new perspectives on the exploitation of MOFs as sacrificial precursors and structural templates in heterogeneous catalysis and eventually contribute to the development of more efficient energy technologies.

\section{Conflicts of interest}

The author declare no conflicts of interest.

\section{Acknowledgements}

The authors are grateful for funding from the Independent Research Fund Denmark (Grant no. 5054-00119 and 611100237) and from Villum fonden (Grant No. 13158). 


\section{References}

1 L. J. Murray, M. Dincă and J. R. Long, Chem. Soc. Rev., 2009, 38, 1294.

2 L. Klebanoff, 2012 Hydrogen storage technology: materials and applications. Section II, 8. Development of ff-Board Reversible Hydrogen Storage Materials. CRC Press. Boca Raton: Taylor \& Francis.

3 A. Klerke, S. K. Klitgaard and R. Fehrmann, Catal. Lett., 2009, 130, 541-546.

4 J. Mielby, A. J. Kunov-Kruse and S. Kegnæs, J. Catal., 2017, 345, 149-156.

5 A. Gallas-Hulin, J. Mielby and S. Kegnæs, ChemistrySelect, 2016, 1, 3942-3945.

6 B. Sakintuna, F. Lamari-Darkrim and M. Hirscher, Int. J. Hydrogen Energy, 2007, 32, 1121-1140.

7 Y. Xia, Z. Yang and Y. Zhu J. Mater. Chem. A, 2013, 1, 9365-9381

8 Y. Yang, F. Zhang, H. Wang, Q. Yao, X. Chen and Z. Lu, J. Nanomater, 2014, 2014, 294350.

9 M. Denney, V. Pons, T. Hebden, D. Heinekey and K. Goldberg, JACS, 2006, 128(37), 12048-12049.

10 W. Chen, J. Ji, X. Duan, G. Qian, P. Li, X. Zhou, D. Chen and W. Yuan, Chem. Commun. 2014, 50, 2142-2144.

11 S. Akbayrak, Y. Tonbul and S. Özkar, Appl. Catal., B, 2016, 198, 162-170.

12 C. Du, Q. Ao, N. Cao, L. Yang, W. Luo and G. Cheng, Int. J. Hydrogen Energy, 2015, 40, 6180-6187.

13 J. Chen, Z.-H. Lu, Y. Wang, X. Chen and L. Zhang, Int. J. Hydrogen Energy, 2015, 40, 4777-4785.

14 S. Akbayrak, M. Kaya, M. Volkan and S. Özkar, Appl. Catal., B, 2014, 147, 387-393.

15 W. Zhan, Q. Zhu and Q. Xu, ACS Catal, 2016, 6(10), 68926905.

16 J. Hu, Z. Chen, M. Li, X. Zhou and H. Lu, ACS Appl. Mater. Interfaces, 2014, 6, 13191-13200.

17 X. Li, C. Zeng, J. Jiang and L. Ai, J. Mater. Chem. A, 2016, 4(19), 7476-7482.

18 S. Kramer, J. Mielby, K. Buss, T. Kasama and S. Kegnæs, ChemCatChem, 2017, 9, 2930-2934.

19 S. Kramer, F. Hejjo, K. H. Rasmussen and S. Kegnæs, ACS Catal. 2018, 8, 754-759.

20 H. Wang, Y. Zhao, F. Cheng, Z. Tao and J. Chen, Catal. Sci. Technol, 2016, 6, 3443- 3448.

21 K. Shen, X. Chen, J. Chen and Y. Li, ACS Catal., 2016, 6(9), 5887-5903.

22 B. Chen, Z. Yang, Y. Zhu and Y. Xia, J. Mater. Chem. A, 2014, 2(40), 16811-16831.

23 B. Liu, H. Shioyama, T. Akita and Q. Xu, JACS, 2008, 130(16), 5390-5391.

24 P. Yin, T. Yao, Y. Wu, L. Zheng, Y. Lin, W. Liu and Y. Li, Angew. Chem. Int. Ed, 2016, 55(36), 10800-10805.

25 C. Wang, J. Tuninetti, Z. Wang, C. Zhang, R. Ciganda, L.
Salmon and D. Astruc, JACS, 2017, 139(33), 11610-11615.

26 Q. Yao, K. Yang, X. Hong, X. Chen and Z. Lu, Catal. Sci. Technol., 2018, 8, 870-877.

27 W. Xia, J. Zhu, W. Guo, L. An, D. Xia and R. Zou, J. Mater. Chem. $A$,2014, 2, 11606-11613.

28 F. Zheng, S. Rassat, D. Helderandt, D. Cald-well, C. Aardahl, T. Autrey and K. Rappé, Rev Sci Instrum, 2008, 79(8), 084103.

29 L. Yang, N. Cao, C. Du, H. Dai, K. Hu, W. Luo and G. Cheng, Mater. Lett., 2014, 115, 113-116.

30 J. Hu, Z. Chen, M. Li, X. Zhou and H. Lu, ACS Appl. Mater. Interfaces, 2014, 6, 13191-13200.

31 X. Feng, and M. Carreon, J. Cryst. Growth, 2015, 418, 158162.

32 J. Meng, C. Niu, L. Xu, J. Li, X. Liu, X. Wang and L. Mai, JACS, 2017, 139(24), 8212-8221.

33 K. Sing, and R. Williams, 2004, Adsorpt. Sci. Technol., 22(10), 773-782.

34 W. Xia, J. Zhu, W. Guo, L. An, D. Xia and R. Zou, J. Mater. Chem. A, 2014, 2, 11606.

35 W. Feng, Y. Wang, J. Chen, B. Li, L. Guo, J. Ouyang, D. Jia, Y. Zhou, J. Mater. Chem. C, 2018, 6, 10-18.

36 Ö. Metin and S. Özkar, Int. J. Hydrogen Energy, 2011, 36, 1424- 1432.

37 H. Wang, Y. Zhao, F. Cheng, Z. Tao and J. Chen, Catal. Sci. Technol., 2016, 6, 3443-3448. 